\title{
Combination of Atrioventricular valve stenosis and regurgitation in fetal heart, a rare but a clinically significant anomaly: A case study
}

\author{
Krishnananda Nayak ${ }^{1}$, Sahana Nayak ${ }^{1}$, Umesh Pai M${ }^{1}$, Rekha V ${ }^{1}$, and Shyamala G ${ }^{2}$ \\ ${ }^{1}$ Manipal Academy of Higher Education \\ ${ }^{2}$ Kasturba Medical College Manipal
}

February 1, 2022

\begin{abstract}
We illustrate a case of atrioventricular valve stenosis associated with insufficiency detected in fetal echocardiography performed in a pregnant woman (22 gestational weeks) of 3rd gravida. The early prenatal diagnosis demonstrated, isolated bilateral atrioventricular value stenosis and insufficiency in the absence of any other associated complex congenital heart diseases such as tricuspid atresia, hypoplastic left heart syndrome, endocardial cushion defect. However, the mother of the affected foetus was found to be normal with no risk factors. Thus, fetal echocardiography plays a pivotal role even in low risk pregnancies for early detection of prenatal cardiac anomalies that guide the obstetricians in determining the risk stratification, therapeutic strategies and prognosis.
\end{abstract}

\section{Introduction}

Antenatal diagnosis of congenital cardiac malformations has become a routine practice in the recent era. Identification of complex congenital heart disease using foetal echocardiography during early pregnancy helps in decision making and management. During foetal cardiac imaging the prevalence of tricuspid regurgitation in structurally normal heart was found to be $6.8 \%$ (1), whereas congenital mitral stenosis is rare, occurring in $0.5 \%$ of patients with congenital heart disease (2). Stenotic lesions of mitral/tricuspid valve most often are associated with concomitant ventricular hypoplasia or great artery atresia, being a part of complex congenital heart disease. In contrast, AV valve stenosis in isolated form is not uncommon, yet show better prognosis compared to multiple anomalies. Number of factors are responsible for causing mitral stenosis which include parachute mitral valve, double orifice mitral valve, mitral valve dysplasia etc; whereas, congenital tricuspid stenosis usually is associated with right ventricular outflow tract obstruction or atresia with secondary hypoplasia of the RV. Combined form of AV valve stenosis is very rare. In this case report we describe the prenatal diagnosis of atrioventricular valve stenosis with bilateral AV valve regurgitation.

\section{Case report}

A 29-year old pregnant woman with G3P2L2, at 21 weeks of twin gestation was referred for fetal echocardiography. Detailed maternal history was reviewed. Anomaly scan done at 21 weeks showed twin A-Hydrops with polyhydramnios and suspected cardiac anomaly whereas twin B was found to be normal. Later she was referred for further evaluation at our center. Anomaly scan performed at this tertiary care center confirmed the presence of twin A-Gross polyhydramnios, nonimmune hydrops, and structurally normal twin B with oligohydramnios. Well ahead the woman was sent for fetal echocardiographic scan to the department of cardiology. Fetal cardiac imaging showed thickened bilateral atrioventricular valves (Figure 1) of twin A, however Twin B had normal cardiac structure and function. Brief cardiac evaluation of twin A demonstrated significant gradient across mitral and tricuspid valve with severe degree of bilateral AV valve regurgitation. Bi-atrial enlargement was evident in twin A. Also, both AV valve stenosis was noted with high gradient noted 
across the valve(Figure $\mathbf{2}$ and $\mathbf{3}$ ). Great arteries were presented slightly smaller in size. Mild pericardial effusion present. Foramen ovale was adequate in size and was shunting from right atrium to left atrium, whereas twin B showed well developed four chambers with no chamber dilatation. AV-VA relation were normal and no complex congenital heart disease noted. Pulmonary veins position and relation was normal. Subsequently, pregnant woman along with spouse was counselled about the case and future associated risks with bilateral AV valve stenosis / regurgitation.

\section{Discussion}

Hydrops fetalis is an abnormal condition in which there is pathological accumulation of excess amount of fluid in $>2$ fetal compartments, including the pleural, pericardial spaces, abdominal cavity or placenta etc(3). Literature describes abnormalities that results in increased venous pressure from volume overload caused by valve regurgitation are among the causes that have been reported $(4,5)$. Nonimmune hydrops associated with AV valve insufficiency makes the prognosis very poor with very high mortality rates (6). Etiology of hydrops are several in which cardiac structural abnormalities include congenital heart defects, arrhythmias, pericardial tumor etc. The prevalence of cardiac abnormalities leading to hydrops account for 10-20\% of prenatally diagnosed non-immune hydrops fetalis (7). Out of all anomalies known, fetal atrioventricular insufficiency is more common compared to stenosis. However, fetal diagnosis of atrioventricular valve stenosis in hydrops fetalis were found to be limited. The present case had combined atrioventricular valve stenosis and regurgitation which is very rare findings and was detected in fetal echocardiography. In such cases, early prenatal diagnosis of atrioventricular valve anomalies helps to rule out causes and aid further management of the disease.

\section{Conclusion}

Mortality rates are found to be very high in infants with hydrops fetalis. Combined atrioventricular valve stenosis with regurgitation is a unique and unusual presentation of congenital heart disease and hence, the causes are unclear. Early prenatal diagnosis with fetal echocardiography is the best modality to assess adverse outcomes and aid in further management.

\section{Declarations}

We obtained the patient's consent to anonymously publish this case.

-Availability of Data and Material: Not applicable

-Conflict of Interest: None declared

-Funding: None

Acknowledgments: We express our sincere thanks to our patient and colleagues, who

made this report possible.

\section{References}

1).Ashraf HH.Pediatric Hydrops Fetalis. Pediatrics: Cardiac Disease and Critical Care Medicine .2017.

2).Silvana M. Congenital Mitral Stenosis. . Pediatrics: Cardiac Disease and Critical Care Medicine .2018.

3). Donofrio MT, Moon-Grady AJ, Hornberger LK, Copel JA, Sklansky MS, Abuhamad A, et al. American Heart Association Adults With Congenital Heart Disease Joint Committee of the Council on Cardiovascular Disease in the Young and Council on Clinical Cardiology, Council on Cardiovascular Surgery and Anesthesia, and Council on Cardiovascular and Stroke Nursing. Diagnosis and treatment of fetal cardiac disease: a scientific statement from the American Heart Association. Circulation . 2014 May 27;129(21):2183-242.

4). Kleinman CS, Donnerstein RL, DeVore GR, Jaffe CC, Lynch DC, Berkowitz RL, et al . Fetal echocardiography for evaluation of in utero congestive heart failure. $N$ Engl J Med. 1982 Mar 11;306(10):568-75. 
5) .Machin GA. Differential diagnosis of hydrops fetalis. Am J Med Genet . 1981;9(4):341-50. 6). Mahony BS, Filly RA, Callen PW, Chinn DH, Golbus MS. Severe nonimmune hydrops fetalis: sonographic evaluation.Radiology . 1984 Jun;151(3):757-61.

7). Yuan SM. Cardiac Etiologies of Hydrops Fetalis. Z Geburtshilfe Neonatol . 2017 Apr;221(2):67-72.

8). Krishnananda N, Ranjan S, Pratap K, Kiran S, Sridevi P, Jyothi S. Congenital Mitral atresia: A rare anomaly diagnosed in fetal echocardiography: A case study. Research Journal of Pharmaceutical, Biological and Chemical Sciences .2016:7(5).

\section{Figure legends}

Figure 1 : Two dimensional fetal echocardiography showing four chamber view with thickened mitral and tricuspid valves.

Figure 2: Color flow mapping across the atrioventricular valve in fetal apical 4 chamber view showing tricuspid stenosis.

Figure 3: Fetal echocardiography showing four chamber view with color flow mapping and continuous Doppler across atrioventricular valves demonstrating both tricuspid stenosis and mitral regurgitation.

\section{Hosted file}

List of figures-AV VALVE STUDY.docx available at https://authorea.com/users/458267/articles/ 554851-combination-of-atrioventricular-valve-stenosis-and-regurgitation-in-fetal-hearta-rare-but-a-clinically-significant-anomaly-a-case-study 